\title{
A GRAMÁTICA DO RÉU: A OBJETIVAÇÃO DO ASSASSINO COMO EXERCÍCIO DE PODER
}

\section{THE GRAMMAR OF THE DEFENDANT: THE OBJECTIFICATION OF THE MURDERER AS POWER EXERCISE}

\author{
Angela Derlise Stübe* e Luiz Fernando Greiner Barp** \\ Universidade Federal da Fronteira Sul, Chapecó, SC, Brasil
}

Resumo: Este trabahaho investiga como o discurso policial, materializado no discurso jornalistico, contribui para a consitiviç̃ão de um sujeito-réu, (re) velando saberes e poderes que circulam em nossa sociedade. Para isso, utilizamos da arquegenealogia de Michel Fouccault como aparato teórico-metodológico e tomamos como corpus de análise duas matérias jornalísticas que detalham a prisão de investigados pelo crime de homićdili. Como resultado, identificamos que o suposto assassino é objetivado a partir de verdades historicamente construídas, que tendem a conduzito para um lugar pré-determinado no dia de seu julgamento.

Palavras-chave: Discurso; Poder; Sujeito; Criminoso; Réu.

Abstract: This article investigates on how the police speech, materialized into the journalistic speech, contributes to the consitituiion of a subject-defendant, (re) vealing knowledge and powers that surround our society. For this purpose we made use of the archaeogenealogy by Michel Fouccult as the theoretical-methodological instrument, and, as the analysis corpus, we took two journalistic articles, which detail the imprisonment of those arrested for homicide crime. As a result, we identified that the supposed murderer is objectified from historically built truths that tend to conduct the subject to a predetermined place on the trial day.

Keywords: Speech; Power; Subject; Criminal; Defendant.

* Professora doutora da Universidade Federal da Fronteira Sul - UFFS, Chapecó, SC, Brasil; angelastube@uffs.edu.br

** Mestrando do PPG em Estudos Linguísticos, da Universidade Federal da Fronteira Sul UFFS, Chapecó, SC, Brasil; barp.I@gmail.com 
Linha D'Água (Online), São Paulo, v. 30, n. 1, p. 127-144, jun. 2017

\section{Introdução}

Em 30 de dezembro de 2015, uma criança indígena, de dois anos, foi assassinada enquanto era alimentada no colo de sua mãe, na rodoviária de Imbituda, região sul de Santa Catarina. Após dois dias, um homem de 23 anos foi preso pela Polícia Civil como suspeito do crime ${ }^{1}$. Em 15 de maio de 2016, a mesma polícia anunciou à imprensa que havia prendido um rapaz de 22 anos, e esse seria o responsável pelo assassinato de uma adolescente na cidade de Joaçaba ${ }^{2}$, Meio-oeste do mesmo estado. O corpo da vítima, morta cerca de um mês antes, foi encontrado em um matagal na cidade vizinha.

Dadas as suas particularidades, os dois crimes muito têm em comum. A morte por si só já é motivo de estranhamento, quando provocada adquire o status de infâmia, delito, crime, barbárie. São verdades construídas ao longo da história que a transformaram em ofensa à sociedade. O responsável por transgredir a lei que impede de matar se torna, então, um inimigo comum, que longe de passar despercebido, precisa agora de uma punição.

Como medida de controle e disciplina, o Estado brasileiro prevê, por meio do Código Penal (doravante CP), determinadas punições para o crime de assassinato, e o encarceramento é hoje a tradicional medida repreensiva. Foucault (1999, p. 142), ao escrever sobre o cárcere, em Vigiar e Punir, afirma que "entre o crime e a volta ao direito e à virtude, a prisão constituirá um 'espaço entre dois mundos', um lugar para as transformações individuais que devolverão ao Estado os indivíduos que este perdera”.

$\mathrm{Na}$ tentativa de encontrar seu responsável, entretanto, qualquer crime tipificado pelo $\mathrm{CP}$, após sua materialização, passa por extensos e detalhados procedimentos dentro do sistema de justiça criminal no Brasil. Esses incluem desde a investigação realizada pela Polícia Civil até a leitura da sentença pronunciada pelo sistema Judiciário. Contudo, se a descoberta de um culpado e a posterior aplicação da pena é uma forma de garantir a ordem, poucos são os homens que decidem

1 Formulação feita a partir de uma pesquisa documental do crime noticiado na mídia, a partir de notícias veiculadas no site Clic RBS (http://www.clicrbs.com.br/).

2 Formulação feita a partir de uma pesquisa documental do crime noticiado na mídia, a partir de notícias veiculadas no site Clic RBS (http://www.clicrbs.com.br/).

STÜBE, A. D.; BARP, L. F. G. A gramática do réu: a objetivação do assassino como 
sobre esse processo. A única forma de a população atuar diretamente se dá, atualmente, por meio do Tribunal do Júri. Nesse órgão, existente desde 1824 no país e visto como espaço democrático, cidadãos comuns julgam se o réu é culpado ou inocente pelo delito pelo qual está sendo acusado.

Atualmente, segundo Brasil (2015), o Tribunal do Júri, ou júri popular, tem sua existência garantida com a Constituição Federal de 1988, que reconhece a sua instituição no Art. 5, inciso XXXVIII. De acordo com o dispositivo constitucional, compete ao órgão o julgamento dos crimes dolosos contra a vida, nas suas modalidades tentadas ou consumadas. Conforme Brasil (2012a), são considerados crimes contra a vida o homicídio (Art. $121 \mathrm{CP}$ ); induzimento, instigação ou auxílio ao suicídio (Art. $122 \mathrm{CP}$ ); infanticídio (Art.123 CP); e o aborto (Art.124 a $127 \mathrm{CP}$ ).

O que propomos neste trabalho, entretanto, não é uma análise do desfecho final do crime, isto é, do julgamento oficial de um acusado, mas sim do que está no início, logo após sua materialização. Se o Tribunal do Júri - espaço de decisão popular - necessita de verdades que possam condenar ou inocentar homens, partimos do pressuposto de que elas começam a ser construídas muito antes. Para que se torne um réu de um julgamento, o suposto criminoso se torna antes suspeito, e é neste momento que pretendemos nos deter. Tal status, que nada tem de honroso, surge quando a polícia investiga e encontra um ou mais possíveis culpados que, após um eventual júri, tornar-se-ão vítimas ou infames para o corpo social.

No ensino do Direito-penal, o assassinato e o julgamento do autor recebe uma atenção especial a partir da compreensão de códigos e leis, além da própria doutrina jurídica. Reforçamos que não cabe, neste trabalho, tecer qualquer juízo de valor sobre o sistema de justiça criminal condenar ao absolver determinados homens, bem como a forma com que tais procedimentos ocorrem. O que propomos é investigar a constituição do sujeito-réu por determinadas práticas discursivas que antecedem o dia do seu veredicto, entendendo que a verdade sobre ele é produzida no e pelo discurso, por meio de relações de poder. Com isso, pretendemos oferecer ao ensino e à pesquisa jurídica outro olhar acerca desse tipo de crime, a partir de um diálogo entre o Direito e a Linguística.

Ao longo deste trabalho, buscaremos interpretar as camadas dos discursos policial e jornalístico, tendo como hipótese que eles objetivam o suspeito de um 
Linha D'Água (Online), São Paulo, v. 30, n. 1, p. 127-144, jun. 2017

crime, constituindo uma verdade discursiva sobre ele e que pode repercutir no dia do seu julgamento, haja vista que o mesmo será feito por cidadãos leigos, isto é, que pouco ou nada possuem de conhecimento sobre nossos códigos punitivos. $\mathrm{O}$ poder, nesse caso, se divide entre diferentes e sujeitos e instituições, sendo configurado como micro-poderes, como elenca Foucault (2001).

Como corpus, optamos por duas matérias jornalísticas publicadas no site Clic $R B S$, plataforma online do maior grupo de comunicação do Sul do Brasil (Grupo RBS), intituladas "Assassino de menino indígena responderá por homicídio doloso duplamente qualificado" e "Jardineiro é preso por assassinato de adolescente em Joaçaba, no Meio-Oeste"4. Utilizamos como critério de seleção conteúdos que detalham e/ou justificam a prisão de suspeitos de praticarem crimes de grande comoção popular em Santa Catarina, ocorridos no primeiro semestre do ano de 2016.

Escolhemos os casos acima, pois, por se tratarem de dois assassinatos, os supostos autores dos crimes serão julgados por um Tribunal do Júri, local em que os responsáveis por condená-los ou absolvê-los não têm ligação direta com o sistema de justiça criminal.Já os recortes analisados nas matérias jornalísticas dizem respeito a enunciados que carregam as vozes de delegados, ou seja, homens responsáveis pela investigação e prisão dos sujeitos apontados como os autores dos delitos em questão.

Por compreender que o trabalho de investigação criminal é silencioso, consideramos que o único espaço em que informações sobre esses sujeitos são divulgadas antes do julgamento ocorre pela mídia, que tende a acompanhar o desenrolar das investigações de crimes de grande visibilidade. Contudo, entendemos o jornalismo inserido no que Foucault (2014) chama de ordem do discurso, que exclui e controla o que é dito. Por conta disso, seu discurso necessita se legitimar na voz oficial, neste caso, na Polícia Civil, que investiga a autoria de um crime e tem o delegado como porta-voz.

3 Conteúdo disponível em: http://dc.clicrbs.com.br/sc/noticias/noticia/2016/01/assassino-de-menino-indigena-respondera-por-homicidio-doloso-duplamente-qualificado-4960769. html. Acesso em: 02 Jul. 2016.

4 Conteúdo disponível em: http://osoldiario.clicrbs.com.br/sc/noticia/2015/05/jardineiro-e-preso-por-assassinato-de-adolescente-em-joacaba-no-meio-oeste-4761932.html. Acesso em: 02 Jul. 2016.

STÜBE, A. D.; BARP, L. F. G. A gramática do réu: a objetivação do assassino como 
Linha D'Água (Online), São Paulo, v. 30, n. 1, p. 127-144, jun. 2017

Utilizaremos como aparato teórico-metodológico a arquegenealogia de $\mathrm{Mi}$ chel Foucault. A partir de uma diferenciação descrita pelo próprio autor, entendemos que "enquanto a arqueologia é o método próprio à análise da discursividade local, a geneaologia é a tática que, a partir da discursividade local assim descrita, ativa os saberes libertos da sujeição que emergem dessa discursividade (FOUCAULT, 2001, p. 172).

\section{Corpo teórico-metodológico}

Desde o aparecimento das Ciências Humanas, no final do século XIX, o sujeito tornou-se um objeto privilegiado de investigação. Como uma inquietação quase narcísica, o homem passou a produzir saberes sobre si mesmo, definindo patologias e classificando condutas, fazendo do conhecimento científico um objeto de poder. Se nos propomos a investigar a objetivação do sujeito-réu é porque nos reconhecemos inseridos nesse espaço de disputas epistemológicas, em que transitamos entre o medo e a necessidade de validação de nossos discursos.

Ao pensarmos nos sujeitos constituídos pelos discursos policial e jornalístico, nos filiamos à perspectiva arquegenealógica de Michel Foucault e entendemos que eles não são livres, pelo contrário, encontram-se submersos em relações de saber e poder. Compreendemos, ainda, que sua constituição se dá na história, pelo discurso enquanto acontecimento e também pelas epistemes e práticas consideradas verdadeiras em uma determinada época.

Nesse sentido, entendemos o sujeito-réu a partir de sua relação com a verdade, aceitando que ela o objetiva, disciplina e subjetiva. Entretanto, não falamos de uma verdade universal e atemporal, mas sim de uma verdade produzida, que conforme Foucault (2001), não pode ser separada do poder. Segundo o autor, cada sociedade cria um regime de verdades centrada na ciência e são os discursos e as instituições que as fazem circular. A partir disso, forma-se o que ele chama de "jogos de verdade", isto é, uma disputa para separar e validar o verdadeiro em oposição ao falso.

Assumindo tais posicionamentos, consideramos os discursos policial e jornalístico como decisivos para compreendermos a constituição do sujeito-réu, já que eles também funcionam como uma espécie de ponte entre os saberes dados como 
Linha D'Água (Online), São Paulo, v. 30, n. 1, p. 127-144, jun. 2017

verdadeiros e os poderes disseminados em uma determinada sociedade, objetivando diferentes sujeitos. Pensamos, entretanto, não no discurso enquanto um conceito teórico, mas sim enquanto prática, ou seja, em funcionamento e relacionado com outras práticas, o que lhe permite também ser um mecanismo de disputa e poder.

Certamente os discursos são feitos de signos; mas o que fazem é mais que utilizar esses signos para designar coisas. É esse mais que os torna irredutíveis à língua e ao ato de fala. É esse "mais" que é preciso fazer aparecer e que é preciso descrever (FOUCAULT, 2015, p. 60).

Ao the conferirmos um status de objeto de desejo, como propõe Foucault (2014), não nos surpreende que sua produção seja "controlada, selecionada, organizada e redistribuída por certo número de procedimentos que têm por função conjurar poderes e perigos [...]" (FOUCAULT, 2014, p. 8-9). Portanto, quando considerarmos o discurso policial presente no discurso jornalístico, nós lhe damos o mesmo peso de uma arma utilizada em nome da lei.

Discorremos até aqui sobre discurso como um dos responsáveis pela constituição do sujeito a partir do momento em que está ligado com a (re)produção da verdade. Consideramos, então, necessário fazer uma definição um tanto quanto material do que entendemos por discurso. Foucault (2015) o conceitua como um conjunto de enunciados que se apoiam na mesma formação discursiva. Sendo assim, o discurso pode ser entendido como uma teia de enunciados que, mesmo pertencendo a campos de saber diferentes, obedecem a um determinado sistema de regularidades e/ou dispersões, possuindo, ainda, uma base histórica e se construindo na prática, quando coloca determinados enunciados em funcionamento.

Importante ressaltar que o enunciado, para o autor, ultrapassa a simples noção de formulação linguística. Ele é considerado uma condição de existência e de materialidade dos sentidos e não se restringe ao verbal. Para Foucault (2015), um enunciado precisa deixar uma "marca", ocupar um lugar e situar-se no tempo. Logo, o que torna uma frase um enunciado é sua função enunciativa: "o fato dele ser produzido por um sujeito em um lugar institucional, determinado por regras sócio-históricas que definem e possibilitam que ele seja enunciado" (GREGOLIN, 2004, p. 89). O que nos interessa nos discursos policial e jornalístico, então, 
Linha D'Água (Online), São Paulo, v. 30, n. 1, p. 127-144, jun. 2017

não é descrever somente o que se diz, mas como se diz e a relação disso com o sujeito e a história.

Trazemos ainda noção de formação discursiva que se torna necessária para pensar no discurso em funcionamento, já que é ela quem lhe delimita.

No caso em que se puder descrever, entre um certo número de enunciados, semelhante sistema de dispersão, e no caso em que os objetos, os tipos de enunciação, os conceitos, as escolhas temáticas, se puder definir uma regularidade [...] diremos, por convenção, que se trata de uma formação discursiva (FOUCAULT, 2015, p. 47).

A formação discursiva acaba por ter uma função teórico-metodológica para Foucault, haja vista que reconhece a singularidade do enunciado ao mesmo tempo em que lhe agrupa em discurso, a partir da dispersão e da regularidade de sentidos que ele produz. Sentidos esses que não podem ser vistos livres das relações entre os poderes e saberes que o perpassam. Tais materialidades e individualidades não se comunicam pelo simples encadeamento lógico de suas proposições ou recorrência de assuntos, mas sim pela positividade de seus discursos. Em outras palavras, pela referência a um mesmo saber, que ultrapassa os limites cronológicos e geográficos. A positividade, então, desempenha um papel que o autor chama de a priori histórico.

Frisamos aqui que não estamos ignorando a singularidade e raridade de um enunciado, considerando que ele seja somente uma repetição, mas o reconhecemos inseridos em sistemas que, sustentados nas práticas e agrupado pelas formações discursivas, garantem a permanência de saberes em uma sociedade. Tais sistemas, Foucault (2015, p. 158) propõem chamar de arquivo: "a lei do que pode ser dito, o sistema que rege o aparecimento dos enunciados como acontecimentos singulares".

O conceito de arquivo, portanto, nos obriga a tratar os enunciados não como documentos, mas sim como monumentos, isto é, como acontecimentos que possuem regras que garantem seu aparecimento em determinada cultura. A leitura de Revel (2005) sobre o arquivo foucaultiano entende que ele representa o conjunto de discursos de uma determinada época e que se mantém através da história. É como se houvesse, então, um fio condutor de discursos que os faz se materializarem ao longo da história. Enquanto arquegenealogistas, ao aceitarmos a existência do arquivo, consideramos que:

STÜBE, A. D.; BARP, L. F. G. A gramática do rév: a objetivação do assassino como 
[...] entre a tradição e o esquecimento, ele [o arquivo] faz aparecerem as regras de uma prática que permite aos enunciados subsistirem e, ao mesmo tempo, se modificarem regularmente. É o sistema geral da formação e da transformação dos enunciados (FOUCAULT, 2015, p. 159).

Por fim, por tratarmos neste trabalho de um discurso materializado em outro (o policial presente no discurso jornalístico), optamos por trazer à luz as discussões que Authier-Revuz $(1998,2004)$ faz sobre a heterogeneidade enunciativa. A autora se filia aos pressupostos teóricos de Mikhail Bakhtin sobre dialogismo e polifonia, bem como a psicanálise lacaniana. Reconhecemos em seus estudos certas divergências com a arquegenealogia foucaultiana, mas acreditamos que ambos os autores possam dialogar em virtude do nosso corpus, desde que respeitadas determinadas singularidades.

Segundo ela, tais heterogeneidades são apresentadas de duas maneiras: de forma constitutiva ou mostrada. Neste momento, dedicamo-nos a heterogeneidade mostrada, haja vista estar presente nos recortes enunciativos que analisaremos. Logo, a voz do outro (da polícia) será linguisticamente detectada na estrutura do texto jornalístico por meio do discurso direto (doravante DD) e indireto (doravante DI).

Tradicionalmente, a gramática costuma tratar, de acordo com Authier-Revuz (2004), que no DI o sujeito (entendido pela autora como locutor) faz uso de suas próprias palavras para remeter ao outro. Já no DD são as palavras do outro que ocupam o discurso e o sujeito funciona como uma "porta-voz".

Entretanto, afastamo-nos de tal conceituação transparente e acreditamos que o DD não é nem objetivo nem fiel a voz do outro, uma vez que "reproduzir a materialidade exata de um enunciado não significa restituir o ato de enunciação - do qual o enunciado é (apenas) o "núcleo" - na sua integralidade" (AUTHIER-REVUZ, 1998, p. 134). Já o DI, por mais que, aparentemente, pareça uma forma subordinada ao DD, é construído a partir de uma tradução do discurso relatado do outro.

[...] trabalhamos com os DD/DI como dois modos radicalmente distintos de representação de um outro ato de enunciação: um, o DD, correspondendo a uma operação de citação da mensagem do ato relatado; o outro, o DI, como uma operação de reformulação, isto é, de produção de um enunciado como tendo o mesmo sentido que ato relatado (AUTHIER-REVUZ, 1998, p. 150).

STÜBE, A. D.; BARP, L. F. G. A gramática do rév: a objetivacạ̃o do assassino como 
Linha D'Água (Online), São Paulo, v. 30, n. 1, p. 127-144, jun. 2017

Por conta de tais posicionamentos que aceitamos e reconhecemos em nosso corpus, admitimos que, por mais que busquemos analisar o discurso policial materializado no discurso jornalístico, ambos objetivam o sujeito-réu, conforme demonstraremos na próxima seção. Acreditamos que o jornalismo dê voz à polícia, entretanto, não ignoramos as reformulações e os deslocamentos de sentido que um discurso cria sobre o outro.

\section{Verdades sobre o assassino}

Por intermédio da arquegenealogia, entendemos que o sujeito é construído pela história a partir da produção de verdades. Ou seja, "o sujeito foi sendo constituído por longos, árduos e conflituosos acontecimentos discursivos, epistêmicos e práticos" (ARAÚJO, 2008, p. 95). O assassino, então, não tem uma conduta, uma motivação ou uma justificativa dada a priori e que seja autônoma. As ciências que o estudam são quem the tornam o que é, objetivando-o e fazendo com que ele se subjetive.

Então, como compreender quem são esses homens acusados de uma glória reversa que, descumprindo o Código Penal, atentam sobre uma vida que não é sua? Aceitando que nossas interpretações estão subordinas a saberes e poderes que também nos condicionam, buscaremos a partir de agora indicar possíveis respostas que detectamos no discurso da polícia e do jornalismo a partir dos dois crimes já mencionados: a morte de uma criança indígena (doravante $\mathrm{C} 1$ ) e o assassinato de uma adolescente (doravante $\mathrm{C} 2$ ).

Ressaltamos, como base em Lenza (2007), que as apuração de infrações penais (com exceção das militares e aquelas de competência da Polícia Federal), ficam a cargo da Polícia Civil de cada estado, sendo que são dirigidas pelos delegados. Brasil (2012b, p. 31), trata o delegado como autoridade policial e, entre as suas atribuições, está a de "fornecer às autoridades judiciárias as necessidades à instrução e julgamento dos processos”. Por ser o responsável pela condução das diligências investigativas, também acaba por ser a voz oficial da Polícia Civil ao explanar o andamento das investigações criminais à imprensa. Portanto, sua voz é superior dentro de tal instituição e é nela que pretendemos nos deter a partir de agora. 
Linha D'Água (Online), São Paulo, v. 30, n. 1, p. 127-144, jun. 2017

SD1: "- De forma fria e serena, ele declarou ter sacrificado o menino por ser uma criança, o que causaria grande impacto na sociedade.”

A sequência discursiva (SD) acima refere-se a voz do delegado responsável pela investigação do $\mathrm{C} 1$ inserida por meio de $\mathrm{DD}$ na matéria jornalística. Ao tentar reconstruir o depoimento concedido pelo suspeito do crime, ele se posiciona e opina. "De forma fria e serena" afirma que o homem "declarou ter sacrificado o menino por ser uma criança". Notemos que ao apontar uma frieza e uma serenidade do investigado durante seu depoimento à polícia, o delegado lhe objetiva, isto é, abre mão da simples narrativa de um fato para dizer o que pensa sobre o suposto homicida. $\mathrm{O}$ assassino se torna, então, não apenas quem mata, mas quem não sente remorso pelo o que faz.

Ao falar em serenidade, o enunciado do delegado, mesmo pertencendo a uma formação discursiva jurídica, define não somente a materialidade e/ou culpabilidade do crime, mas sim as condições psicológicas de quem o teria cometido. SD1 conduz, também, para a validação da razão, eliminando a possibilidade de um crime praticado por outro motivo senão pela vontade própria.

Tal separação entre razão e desrazão aparece em $A$ ordem do discurso, quando Foucault (2014) escreve sobre os procedimentos que controlam e excluem os discursos de nossa sociedade. Conforme o autor, “[...] o louco é aquele cujo discurso não pode circular como o dos outros: pode ocorrer que sua palavra seja considerada nula" (FOUCAULT, 2014, p. 10). Nesse sentido, podemos interpretar que ao garantir a serenidade do suspeito, a SD1 conduz para a validação da confissão do crime ocorrida por meio de interrogatório e busca evitar que a alegação da loucura possa absolvê-lo.

A utilização do interrogatório, prática tradicional durante a investigação de um crime, pretende, por meio dos depoimentos do suspeito ou testemunhas, reatualizar o fato na intenção de encontrar a verdade sobre ele. Entretanto, mais do que isso, conforme Foucault (1999), ele é uma forma de exercitar o poder, uma vez que funciona como suplício da verdade.

Apesar de o interrogatório, normalmente, não ser a única prova utilizada para definir o culpado por um crime, acreditamos ele possui um peso tão forte que 
Linha D'Água (Online), São Paulo, v. 30, n. 1, p. 127-144, jun. 2017

quase liberta a justiça da obrigação de fornecer outras provas. De acordo com Foucault (1999), ele permite que a verdade exerça todo o seu poder, uma vez que o suspeito pode tomar para si o crime e assinar sua confissão. Ao informar que o homem investigado "declarou ter sacrificado o menino", SD1 reduz as possibilidades de questionar tal verdade, uma vez que não há mais nada a ser dito sobre o suposto culpado, pois ele mesmo já se reconhece como tal.

A utilização do verbo "declarar" nos aponta para um arquivo de discursos oficiais que ganha o peso da absoluta certeza. Logo, o enunciado não deixa brechas para a dúvida, uma vez que pressupõe que, coberto da razão, o suspeito reconheça o peso de sua infâmia. Resta a ele aceitar e cumprir a pena que a justiça do homem lhe conferir.

A preocupação em garantir que o criminoso cumpra essa pena, por sinal, também é evidenciada em enunciados sobre o $\mathrm{C} 1$ quando, por meio do DI, a voz do delegado surge e garante:

SD2: "O policial disse também que, mesmo que uma pessoa tenha comprovadamente um problema de origem psíquica e cometa um crime, não significa que deixará de cumprir a pena. Neste caso, o que muda é a forma. Em vez de uma penitenciária, por exemplo, deve ser levado para um hospital de custódia, onde cumprirá medida de segurança, e não exatamente uma pena."

No recorte acima grifado nos chama a atenção como o discurso jornalístico, mesmo buscando reproduzir fielmente a voz da polícia, desliza de sentido. Atribuindo autoria ao delegado, inicialmente formula que "mesmo que uma pessoa tenha comprovadamente um problema de origem psíquica e cometa um crime, não significa que deixará de cumprir a pena" para logo em seguida enunciar que se trata de uma medida de segurança e "não exatamente uma pena". Tais interpretações nos levam a concordar com Authier-Revuz (1998), quando diz que o DI trata-se de uma tradução, sujeita a transformações estruturais e de sentido. A partir disso, consideramos que na SD2 ambos os discursos (policial e jornalístico) objetivam o assassino, mas conforme formações discursivas distintas. 
O gesto de interpretação permite compreender que a polícia tenta garantir a punição, independente das condições psicológicas que possam ser atestadas sobre o possível autor. Amparada novamente em um arquivo, isto é, nas positividades de seu discurso, enuncia segundo o que a formação discursiva na qual está inscrita permite enunciar: se louco ou são, não sairá imune frente à barbárie que cometeu. Tal enunciado também produz uma verdade pelo jogo de regras discursivas que circulam em nossa época, e está diretamente ligado com a massa de textos pertencentes à mesma formação discursiva da polícia, que preza pela justiça e pela punição.

Essa verdade, ao mesmo tempo, revela também um poder de controle que se desdobra sobre o suspeito. Conforme Candiotto (2003, p. 24), a verdade é inseparável das relações de poder entre as práticas sociais, uma vez que "além de ser efeito do jogo de regras entre os saberes, a verdade do sujeito passa a ser pensada também como efeito de estratégias de poder de uma sociedade”.

De acordo com Foucault (1999), mesmo que não recorra ao castigo violento ou sangrento, que nesse caso podemos interpretar como o encarceramento, o sistema punitivo - sistema esse em que a polícia se inscreve - precisa corrigir o indivíduo transgressor, mesmo que isso ocorra em um hospital de custódia.

[...] mesmo quando utilizam métodos "suaves" de trancar ou corrigir, é sempre do corpo que se trata - do corpo e de suas forças, da utilidade e da docilidade delas, de sua repartição e de sua submissão (FOUCAULT, 1999, p. 28).

Consideramos, entretanto, que devido à ordem discursiva de cada época e sociedade, nem tudo pode ser dito por qualquer um, haja vista que o poder também delimita lugares de fala. Por conta disso, quando desliza e se posiciona na voz da polícia, o jornalista utiliza da denegação para dizer que o hospital de custódia não se trata exatamente de uma pena. Inserido em uma formação discursiva profissional, que lhe atribui um papel de imparcialidade, ele ameniza a intensidade da punição, pois não tem autorização e liberdade castigar abertamente.

Nossa interpretação se solidifica quando consideramos "O policial disse" também presente na SD2. Durante toda a matéria jornalística a voz do outro, isto é, o discurso da polícia, aparece referenciado na voz de um delegado. Nesse recorte, porém, o mesmo sujeito é denominado como policial. Como já 
evidenciado anteriormente, de acordo com o Código de Processo Penal (CPP), o cargo de delegado é caracterizado como autoridade policial. A partir da hierarquia presente na instituição Polícia Civil, consideramos que ao substituir a designação de delegado para policial, o discurso jornalístico diminui o status que a voz do outro possui. Com tal modalização, reforça sua formação discursiva profissional e arma uma disputa entre discursos.

Sintetizando nossas interpretações sobre SD2, enquanto o discurso policial objetiva o investigado, indicando que a punição precisa ocorrer independente das condições psíquicas do autor; o discurso jornalístico deixa marcas que buscam alcançar uma neutralidade - ilusória - que os princípios da profissão lhe cobram. Entretanto, a objetivação do jornalismo não desaparece, pelo contrário, está aliada com aquela feita pela polícia, uma vez que ao traduzir da voz do delegado realiza escolhas sobre o ato enunciativo em uma anterior entrevista.

Vimos até aqui que em relação ao $\mathrm{C} 1$, tanto o discurso policial quanto o jornalístico reforçam a confissão e reafirmam que o suposto criminoso necessita ser punido, por mais que de formas diferentes. Contudo, por mais que julgue e se posicione em suas falas, a voz do delegado não se reconhece enquanto justiça:

SD3: "Ele explicou que, por hora, não vê motivo para a transferência do preso para outra instituição. Se isso ocorrer, diz, será uma decisão da Justiça."

Ao traduzir e expor o que a polícia diz, o enunciado revela que o delegado, por mais que objetive e defina o réu como um culpado (SD1 e SD2), o entende afastado do poder de decidir pela manutenção das condições de existência do suspeito do crime. A formulação linguística "Se isso ocorrer, diz, será uma decisão da Justiça", demonstra que os sujeitos, neste caso o delegado, podem ocupar diferentes posições no discurso.

Nos próximos recortes tentaremos demonstrar como a objetivação, tanto em DD quanto em DI, também se apoia em fatores externos ao crime. O homicida suspeito tem sua vida vasculhada na intenção de justificar ou não a conduta pela qual está sendo investigado e, posteriormente, julgado. Os recortes analisados, por sua vez, 
Linha D'Água (Online), São Paulo, v. 30, n. 1, p. 127-144, jun. 2017

agora dizem respeito ao $\mathrm{C} 2$, isto é, ao assassinato de uma adolescente, supostamente cometido por um homem de 22 anos na região de Joaçaba, em Santa Catarina.

SD4: "O delegado afirmou que $\mathrm{SH}^{5}$ é casado e mantinha uma relação com $\mathrm{VH}^{6}$, tendo decidido matá-la após uma briga, pois ela pedia para que ele assumisse o namoro."

Na SD4 percebemos como o jornalismo, ao dar voz à polícia, opta por explorar a questão afetiva que o suspeito mantinha com a vítima. Ao afirmar que o possível criminoso "é casado e mantinha uma relação com $V H$ " o enunciado tende a conduzir o suspeito para um julgamento moral. Tal constatação se fortifica quando analisamos o restante da sequência, que relata o motivo pelo qual o suspeito teria decidido pelo crime: "após uma briga, pois ela pedia para que ele assumisse o namoro.".

Há no enunciado, então, a exploração da motivação do crime, supervisionada pela verdade da monogamia. Verdade essa, segundo Candiotto (2003), estabelecida pelo jogo de regras, pela ordem do discurso que condiciona saberes. Logo, a SD4 evidencia que o investigado, além de ter matado a vítima, também traia sua esposa.

O crime de homicídio, portanto, não seria a única transgressão cometida pelo suspeito, uma vez que ele também seria o autor do crime social da traição. Com base nessa interpretação, a SD4 nos aponta para duas vítimas: aquela assassinada após pedir para que o relacionamento viesse a público e aquela desrespeitada, que confiando no esposo, o viu traí-la com outra mulher.

Consideramos, novamente, que a verdade acima mencionada é histórica, vindo à tona a partir da noção de arquivo. A dificuldade de descrevê-lo, entretanto, surge porque se fala no interior de suas próprias regras, ou seja, a partir das regras que garantem a permanência ou exclusão de determinados discursos ao logo da história. Logo, traição como atenuante do crime na SD4 não surge como uma tentativa consciente de qualificá-lo ainda mais, uma vez que o arquivo que a sustenta "dá ao que podemos dizer [...] seus modos de aparecimento, suas formas de existência e de coexistência, seu sistema de acúmulo, de historicidade e de desaparecimento" (FOUCAULT, 2015, p. 159).

SH: suspeito de homicídio.

$6 \mathrm{VH}$ : vítima de homicídio.

STÜBE, A. D.; BARP, L. F. G. A gramática do réu: a objetivação do assassino como 
Linha D'Água (Online), São Paulo, v. 30, n. 1, p. 127-144, jun. 2017

Como para nossas interpretações também nos interessa a forma como se diz algo, destacamos também na SD4 a utilização do verbo "pedir" quando utilizado para recordar a atitude da vítima, que "pedia para que ele [o suspeito] assumisse o namoro" que havia entre ambos. Diferente de outras formulações que poderiam ter sido construídas na intenção de se referir a mesma situação, tais como "cobrava", "exigia", "solicitava", o verbo "pedir" demonstra uma não autoridade enunciativa. Logo, a estrutura linguística do enunciado também conduz para relação desigual entre homem e mulher, ou ainda, entre possível criminoso e jovem assassinada.

SD5: "- Ele era casado, disse que ficou com receio e na briga acabou matando a menina. Os dois tinham uma relação próxima, amorosa, tanto que ela confiou nele e entrou no veículo - destacou o delegado [...].”

A verdade do casamento aparece por mais de uma vez na matéria sobre o $\mathrm{C} 2$. Ao reforçar na SD5, tanto em DI quanto DD, a conduta do adultério, a objetivação do suposto criminoso busca criar um modelo de homicida a partir de práticas pessoais. Como se separasse de forma maniqueísta o delinquente do cidadão honesto, o discurso jornalístico, aliado como o policial, introduz informações além da materialidade do crime na intenção de validar seu discurso. Ao dizer, ainda, que "ela [a vítima] confiou nele" a SD5 também atribuiu outras características negativas ao investigado. Tal homem, pela voz do delegado é, além de assassinado, traidor e mentiroso.

A partir da leitura que Foucault (2013) faz sobre o caso de Pierre Rivière, em Eu, Pierre Rivière, que degolei minha mãe, minha irmã e meu irmão... percebemos nos recortes sobre o $\mathrm{C} 2$ que importa muito mais para tais discursos não o crime que ocorreu, mas sim sua forma e condições. São as verdades produzidas em torno do acontecimento que o darão a intensidade que se almeja para o crime e, consequentemente, para o seu posterior julgamento. Conforme Foucault (1999, p. 113), "a proporção entre a pena e a qualidade do delito é determinada pela influência que o pacto violado tem sobre a ordem social”. Dessa forma, o crime lança o investigado contra todo o corpo social, permitindo que a sociedade se levante para puni-lo e tornando-o um inimigo comum. 
Linha D'Água (Online), São Paulo, v. 30, n. 1, p. 127-144, jun. 2017

Com isso, vemos nas práticas discursivas que discutem a conduta dos investigados pelo crime de homicídio as relações do discurso com o poder, uma vez que disseminam verdades que tendem a conduzir para um eventual julgamento, seja ele moral ou penal. Conforme Araújo (2008), o discurso não se refere somente a um conjunto de regras linguísticas, uma vez que faz parte do jogo de estratégias, tornando-se alvo de lutas e objeto de polêmicas. O saber, o discurso, o poder e a verdade estão diretamente imbricados e influenciando um ao outro.

\section{Considerações finais}

Concluímos nossas análises com a certeza de que não dissemos tudo, uma vez que também estamos inscritos em determinadas formações discursivas. Enquanto sujeitos, nos reconhecemos inseridos em "jogos de verdade”, o que faz de nossas interpretações um reflexo dos saberes e poderes de nossa época. Entretanto, esperamos que as verdades que aqui tecemos possam se fixar na história, servindo como registro futuro e objeto de eventuais reflexões tanto na prática profissional, como no ensino e pesquisa que buscam a formação de profissionais capacitados para trabalhar com a ciência jurídica e/ou linguística.

A partir das análises realizadas acerca dos dois crimes ocorridos em Santa Catarina e reproduzidos em matérias jornalísticas, percebemos que tanto o discurso policial quanto o jornalístico influenciam na constituição de um sujeito-réu. Sua objetivação obedece às singularidades de cada crime, ao mesmo tempo que são reguladas pela ordem discursiva de um momento histórico e social.

Consideramos que o discurso da polícia, representado pela voz do delegado, tende a se apegar em elementos da investigação para assegurar antecipadamente a culpa do suspeito de um crime. Também busca produzir verdades a partir do diagnóstico de condições psicológicas do investigado na intenção de validar o que diz. Entretanto, reconhece que seu papel institucional de dentro do sistema de justiça criminal não lhe dá permissão para julgar e, quando pode, recua na intenção de não assumir responsabilidades.

O discurso jornalístico, por sua vez, mesmo quando insere a voz do outro, busca uma neutralidade requisitada pela profissão e inscrita em sua formação discursiva. 
Linha D'Água (Online), São Paulo, v. 30, n. 1, p. 127-144, jun. 2017

Contudo, enxergamos tal neutralidade uma ilusão, uma vez que a própria formulação linguística demanda escolhas, o que nos permite interpretar que polícia e jornalismo caminham para uma objetivação que segue os mesmos princípios.

A utilização de questões pessoais, tanto referente à vida do suspeito quanto da vítima, surge como uma prova complementar a materialidade do crime, dificultando uma posterior defesa do investigado, haja vista que estimula um julgamento moral. Os discursos policial e jornalístico, então, vasculham e expõem os resquícios de uma vida antes do delito na intenção de confirmar a autoria do crime.

As interpretações que trouxemos até aqui nos fazem acreditar que o suposto criminoso é objetivado a partir de verdades impostas historicamente e que buscam normalizá-lo e qualificá-lo como bom ou ruim não somente a partir do crime que teria cometido. Tais discursos, então, indicam para as estratégias de um poder disciplinar, que conforme Foucault (1999), busca adestrar e normalizar indivíduos. Quando falamos nesse adestramento, entretanto, não nos referirmos somente ao criminoso, uma vez que a objetivação de sua conduta também serve de exemplo àqueles livres do sangue derramado por um crime.

\section{Referências}

AUTHIER-REVUZ, Jacqueline. Observações no campo do discurso relatado. In: AUTHIER -REVUZ, Jacqueline. Palavras incertas: as não coincidências do dizer. Campinas: UNICAMP, 1998. p. 133-164.

Heterogeneidade mostrada e heterogeneidade constitutiva: elementos para uma abordagem do outro no discurso. In: . Entre a transparência e a opacidade: um estudo enunciativo do sentido. Porto Alegre: EDIPUCRS, 2004. p. 11-80.

ARAÚJO, Inês Lacerda. Foucault e a crítica ao sujeito. 2a ed. Curitiba: Editora da UFPR, 2008.

BRASIL. Constituição (1988). Constituição da República Federativa do Brasil. 48a ed. Brasília: Edições Câmara, 2015.

BRASIL. Código Penal (1940). Código Penal, constituição federal e legislação complementar. 18a ed. São Paulo: Saraiva, 2012a.

STÜBE, A. D.; BARP, L. F. G. A gramática do réu: a objetivaç̦̃o do assassino como 
Linha D'Água (Online), São Paulo, v. 30, n. 1, p. 127-144, jun. 2017

BRASIL. Código de Processo Penal (1941). Código de Processo Penal e Constituição Federal e legislação complementar. 18a ed. São Paulo: Saraiva, 2012b.

CANDIOTTO, Cesar. Foucault e a crítica da verdade. $2^{\mathrm{a}}$ ed. Belo Horizonte: Autêntica Editora, 2003.

FOUCAULT, Michel. Vigiar e punir: história da violência nas prisões (1987). 27a ed. Petrópolis: Vozes, 1999.

. Microfísica do poder (1979). 16ª ed. Rio de Janeiro. Graal, 2001.

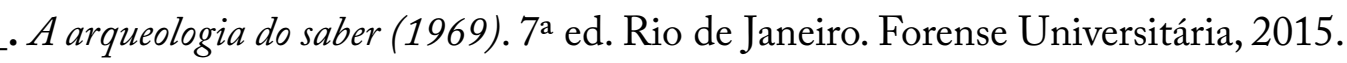

. A ordem do discurso (1970). 24a ed. São Paulo: Loyola, 2014.

. Eu, Pierre Revière, que degolei minha mãe, minha irmã e meu irmão...(1973). 2a ed. Rio de Janeiro: Graal, 2013.

GREGOLIN, Maria do Rosário. Foucault e Pêcheux na construção da análise do discurso: diálogos e duelos. São Carlos: ClaraLuz, 2004.

LENZA, Pedro. Direito Constitucional Esquematizado.11ª ed. São Paulo: Editora Método, 2007.

REVEL, Judith (2002). Michel Foucault: conceitos essenciais. São Carlos: Claraluz, 2005.

Recebido: 26/02/2017.

Aprovado: 31/07/2017.

STÜBE, A. D.; BARP, L. F. G. A gramática do réu: a objetivaç̦̃o do assassino como 